\title{
The effect of detergent as polluting agent on the photosynthetic activity and chlorophyll content in bean leaves
}

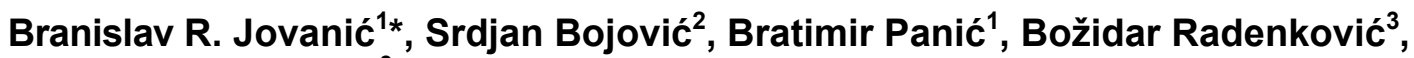 \\ Marijana Despotović ${ }^{3}$
}

\author{
${ }^{1}$ Institute of Physics, Belgrade University, Zemun, Serbia; *Corresponding Author: branislav.jovanic@,ipb.ac.rs \\ ${ }^{2}$ Institute for Biological Research "Siniša Stanković", Belgrade, Serbia \\ ${ }^{3}$ Faculty of Organization Science, Belgrade, Serbia
}

Received 28 October 2009; revised 10 January 2010; accepted 12 January 2010.

\begin{abstract}
The paper investigates effects of detergent for domestic use on the photosynthetic activity and chlorophyll content in intact bean leaves. The plants were watered for $\mathbf{2 1}$ days with a solution of domestic washing powder of $0.60 \mathrm{~g} \mathrm{r} / \mathrm{l}$. It was established that the activity of photosynthetic apparatus in the plant leaf $\mathrm{PhAC}_{\text {Norm }}$ [\%] decreases exponentially with the length of plant treatment/watering. At the end of the treatment $\left(21^{\text {st }}\right.$ day) the activity of photosynthetic apparatus in the dosed plant leaf was no more than $45 \%$ of that in control plant (those which were not watered with detergent solution). With increased plant treatment duration the changed chlorophyll concentration $\Delta \mathrm{Chl}_{\text {Norm }}[\%]$ rose non-linearly in plant leaves. The highest change $\Delta \mathrm{Chl}_{\text {Norm }}[\%]$ was observed on the $21^{\text {st }}$ day and amounted to $12 \%$.
\end{abstract}

Keywords: Chlorophyll; Detergent; Plant; Photosynthesis; Pollution; Water

\section{INTRODUCTION}

High technologies and technological processes are always accompanied with products which pollute the environment to varying extents. Very few of these products are not pollutants. This is the reason why environmental study is becoming increasingly important for the survival of plant and animal world and ultimately of humankind itself. It should be noted that a culprit for environmental pollution should not be sought only in outdated or new technologies. Sources of pollution can be, which is often ignored, some domestic processes in urban environment, such as food preparation or personal hygiene. The subject of this study is an investigation into water pollution resulting from everyday domestic hygienic procedures. There are hardly any households without a washing machine connected with pipes to sewage for discharge of used water with detergent. Used water is discharged into the nearest river or a lake and together with it detergent. Undoubtedly, with time detergent concentration in the river/lake goes up and the direct consequence of this is a dramatic change in the biosphere. Significant pollution in ground water was observed in Tehran [1]. There are other numerous examples of polluted rivers and lakes with industrial detergents. For example it was found out that the Caspian Sea waters and Volga Terek, and Sulak rivers were extremely polluted with a high detergent concentration [2]. The Asa River in Nigeria is dramatically polluted with industrial detergents [3]. Likewise the Coastal Zone of the Sea of Okhotsk and Avacha Bay are polluted with detergents [4]. Regardless whether it is river or lake water, it is used in gardening for watering vegetables used for human consumption. Doubtless, this water will cause changes in vegetables which can have an adverse effect on people eating them.

\section{MATERIAL AND METHODS}

\subsection{Methods}

Bean (Phaseolus vulgaris L.) seeds were grown for 3 weeks. They were placed in a growth chamber adjusted to the identical growing conditions (humidity, lighting, temperature, nutrition of soil). The seedlings were watered daily during all investigated periods with tap water. After this period the plants were divided in two groups: control and stress. Growing conditions were also identical for control and stressed samples and the only difference was the presence or absence of detergent in soil. Concentration of domestic use detergent in the water 
used for watering was $0.60 \mathrm{~g} \mathrm{r} / 1$. The control samples were watered with water without detergent. Therefore, any differences between fluorescent spectra and fluorescence induced curve for stressed versus control plants could only be the result of the presence of detergent.

In all experiments the plant's leaves remain intact (cutting is an additional stress) and we could make several measurements on the same plant at any time. In further text, the subscripts (S) and (C) will denote the stressed or control (nonstressed) conditions, respectively. Photosynthetic activities were determined using well known Kautczhy method. Photosynthesis measurements of light-adapted plants, non-destructive measurements of potential quantum yield $(\mathrm{Fv} / \mathrm{Fm})$, were taken using a photodiode connected with $14 \mathrm{bit} \mathrm{AD}$ card for collecting modulated fluorescence. In front of the photodiode was placed interference filter $690 \mathrm{~nm} \pm 5 \mathrm{~nm}$. Excitation source for fluorescence induction curve was high intensity LED $470 \mathrm{~nm} / 12 \mathrm{~mW}$. The beans were transferred to a darkened laboratory for 5 minutes for adaptation before measuring fluorescence kinetics at $690 \mathrm{~nm}$ [5]. Each point in Figure 1 and Figure 2 represents mean value of 15 measurements on different leaves which completely satisfies the demand for value measurement and calculation precision $\left[\Delta \mathrm{Chl}(\mathrm{a}, \mathrm{b})\right.$ and $\left.\mathrm{PhAc}_{\mathrm{Norm}}\right]$ to be higher than $1 \%[6]$.

For excitation the leaves and obtained fluorescence spectra the leaf was irradiated by high power LED (470 $\mathrm{nm} / 12 \mathrm{~mW}$ ). The fibre inlet was placed $15 \mathrm{~mm}$ from the leaf surface. The LED beam diameter on the leaves was $\sim 10 \mathrm{~mm}$. The LED light beam was always directed onto the upper surface of the leaves at a $90^{\circ}$ angle of the leaf axis, and the optical fibre was set at a $90^{\circ}$ angle to the leaves' surface on the same side. Fluorescence emitted radiation from intact leaf was collected and directed through an optical fibre (N.A. of 0.22 and $1000 \mu \mathrm{m}$ diameter) that was coupled to a portable 2048-element CCD spectrometer (AVANTES 1000 PC). Data collection and spectrum processing were conducted in real time with microcomputer and commercial software OOI Base (AVANTES Inc.). The results for each groups of bean represent an average of the measurement of ten leaves. Fluorescence measurements took $1.5 \mathrm{~min}$ for each measured leaf.

Chlorophyll content $\mathrm{Chl}(\mathrm{a}, \mathrm{b})$ in bean leaf was determined from experimentally obtained fluorescence spectra and well known relation between chlorophyll content and fluorescence intensity ration. It is well known that the ratio of the two chlorophyll fluorescence peaks $\left(\mathrm{F}_{730} / \mathrm{F}_{690}\right)$ in leaves correlates well with amount of chlorophyll content in the bean plant leaves [7]. Therefore chlorophyll content was determined using: a) Fluorescence bean spectra and b) relation between chlorophyll content and the fluorescence intensity ratio FIR defined as the ratio of the fluorescence intensity measured at
$730 \mathrm{~nm}\left(\mathrm{~F}_{730}\right)$ and $690 \mathrm{~nm}\left(\mathrm{~F}_{690}\right) \mathrm{FIR}=\mathrm{FIR}_{690} / \mathrm{FIR}_{730}$. For the bean linear correlation $\left(r^{2}=0.954\right)$ between chlorophyll(a,b) content and FIR is $\operatorname{Chl}(\mathrm{a}, \mathrm{b})=42.93$ 12 FIR and was obtained from literature data [5]. In order to eliminate errors which can appear due to differences in individual chlorophyll contents in different bean samples we introduced a relative change of the chlorophyll $(a, b)$ :

$\Delta \mathrm{Chl}(\mathrm{a}, \mathrm{b})=\operatorname{Chl}(\mathrm{a}, \mathrm{b})_{\mathrm{UV}}-\operatorname{Chl}(\mathrm{a}, \mathrm{b})_{\mathrm{C}}=12\left[\mathrm{FIR}_{\mathrm{UV}}-\mathrm{FIR}_{\mathrm{C}}\right]$

FIR $_{C}$ and FIR $_{U V}$ are the fluorescence intensity ratio for control plant which were not exposed to the UV radiation and the plant which were exposed to the UV radiation. This method was successful in the experiment with a pumpkin exposed to the $\gamma$-nuclear radiation [8].

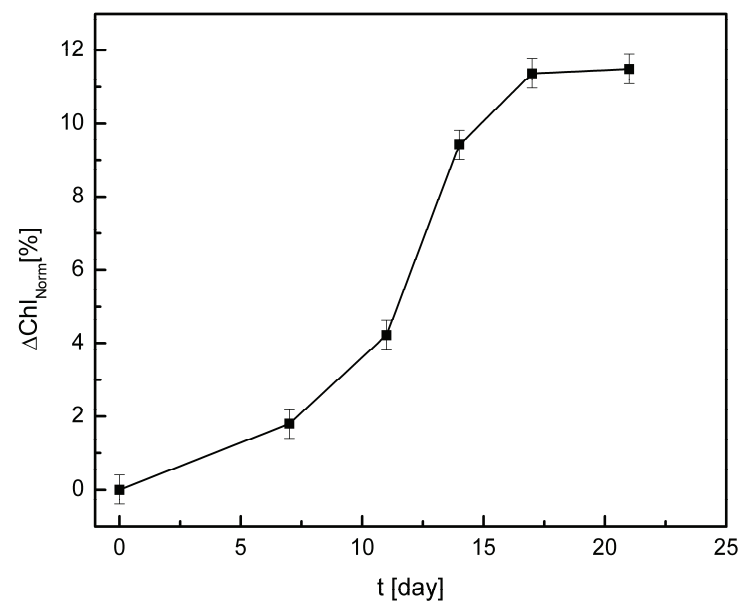

Figure 1. Change in chlorophyll content $\Delta \mathrm{Chl}(\mathrm{a}, \mathrm{b})$ in the bean leaves during irrigation with water contain detergent.

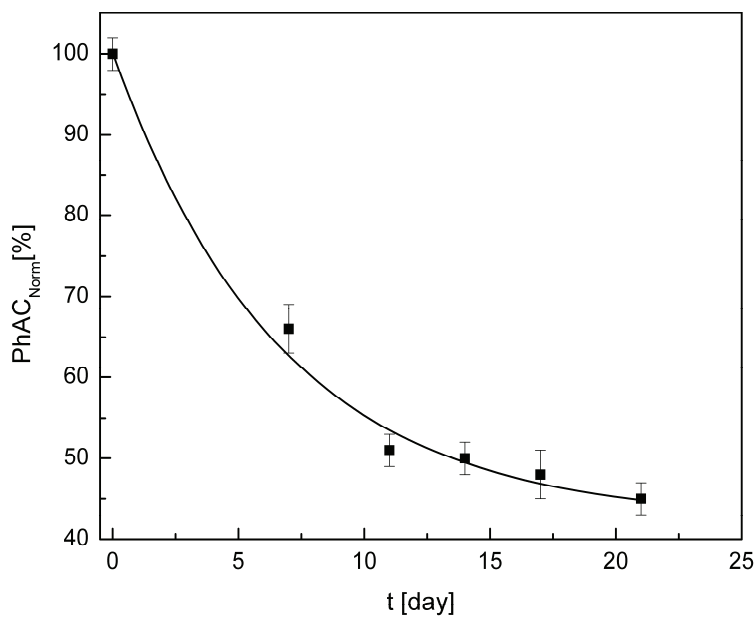

Figure 2. Change of the normalized photosynthesis activity $\mathrm{PhAc}_{\text {Norm }}$ in the bean leaves as function of time exposition to radiation with detergent. 


\section{RESULTS}

To avoid effects of plant age on chlorophyll concentration the control and dosed plants were of the same age, To avoid determining real chlorophyll concentration, relative chlorophyll concentration reduction was determined: chlorophyll concentration in the dosed plants was marked $\Delta \mathrm{Chl}_{\text {Norm }}$ as opposed to the control samples of the same age which were not treated with detergent. The reduction in chlorophyll concentration in the marked values $\Delta \mathrm{Chl}_{\text {Norm }}$ over detergent treatment time is shown in Figure 1. Figure 1 shows that with time relative change of chlorophyll concentration increases quickly to reach its peak on the seventeenth day at about $11.5 \%$. Obviously in this period the detergent has adverse effect on chlorophyll by destroying it constantly. After this the relative change of chlorophyll concentration remains steady at the same value. This pattern can be explained with a hypothesis that the plant adapted to the given unfavourable conditions and developed a mechanism to maintain the reduced chlorophyll concentration.

When determining photosynthetic activity $\mathrm{PhAc}$ of photosynthetic apparatus in a plant leaf, equally when determining reduction in chlorophyll concentration in control and dosed plants, the plants were of the same age to avoid the effect of plant age. To avoid determining absolute photosynthetic activity, relative reduction of $\mathrm{PhAc}$ was determined. The PhAc in detergent treated plant was marked $\mathrm{PhAc}_{\text {Norm }}$ to distinguish them from control samples of the same age which were not treated with detergent. The obtained changes in marked values $\mathrm{PhAc}_{\text {Norm }}$ over the detergent treatment time are shown in Figure 2. Unlike chlorophyll concentration, photosynthetic activity $\mathrm{PhAc}$ constantly, exponentially decreases to reach only $45 \%$ of initial activity on the $21^{\text {st }}$ day. This pattern indicates that this water has adverse effects on plants.

\section{DISCUSSION}

Scientific papers offer data indicating different effects of different detergents on plants. In most cases detergents have adverse effects on plant pigments and morphology and inhibit metabolic processes. It was found the toxic effect of sodium dodecyl sulfate (SDS) and the household synthetic detergents (HSDs) Kristall and Tix (0.1, 1, and $10 \mathrm{mg} / \mathrm{l})$ on the diatom Alga Thalassiosira pseudonana [9]. By the presence in water of detergents for wool domestic washings the native enzyme lost $50 \%$ of activity after $20 \mathrm{~min}$ of incubation [10]. The effect of detergent on plants varies depending on how the plant is exposed to it. For example, when bean was watered with $0.01 \%(\mathrm{w} / \mathrm{v})$ solution the nondenaturing, zwitterionic detergent [3-\{3-cholamidopropyl\}-dimethylammonio]1-propane-sulfonate) $0.01 \%(\mathrm{w} / \mathrm{v})$ it induced root hair deformation [11]. Also, in mungbean (Vigna radiata) seeds synthetic detergent induced reduction in dehydrogenase activity [12]. The leaves completely lost their turgor pressure and displayed chlorosis when they are treated with detergents [13]. The biophysical characteristics of the membrane were changed after detergent (Brij 58) treatment [14]. Detergent inhibited growth, metabolic activity took place only for 1 to 5 days, after which metabolic activity also ceased [15]. Also, high concentration of detergent might cause loss of the native configuration of $\beta$-carotene [16]. Cell growth and fission inhibition, as well as morphological changes and blocking of chlorophyll a synthesis, were recorded at $10 \mathrm{mg} / \mathrm{L}$ concentration of detergent of household synthetic abstergent (HSA) [17]. When $\beta$-carotene is treated with a high concentration of detergent [18] this might cause loss of the native configuration [18]. Higher plant thylakoid membranes can be fractionated with various detergents [19].

As can be seen from our data chlorophyll is sensitive to detergent which tallies with other research results. The plant treated with water content detergents showed high inhibitory effect on chlorophyll content in sunflower leaves [20]. The aggregation of chlorophyll is partly inhibited by detergent Triton X-100 [21]. In addition to reducing its concentration, detergents have other effects on chlorophyll. Studies on light harvesting complexes LHCs show that detergent-induced dissociation of LHCs and caused decline in bonding $\mathrm{Chl} \mathrm{b}$ and $\mathrm{Chl}$ a [22]. The results on pigment-protein complexes of Pisum sativum thylakoids treated with detergent Triton X-100 and n-octyl $\beta$-D-glucopyranoside show that reversible dissociation of pigment-protein complexes occur [23]. Cell growth and fission inhibition on cryptophytic alga Chroomonas salina (Wils.) Butch. (Cryptophyta), as well as morphological changes and blocking of chlorophyll a synthesis, were recorded at $10 \mathrm{mg} / \mathrm{L}$ concentration of household synthetic abstergent (HSA) «Tix» [17] .

In addition to the above discussed effect of detergent on chlorophyll, it was to be expected that similar possibly even identical effect will be observed on photosynthesis. Detergent-induced reversible denaturation of the photosystem reaction [24]. Detergents have strong effect on the fluorescence properties of the light-harvesting complexes of photosystem II [25]. Detergent (Triton $\mathrm{X}-100)$ has effect on relaxation dynamics of photosystem II [26]. Some results have shown that low concentration of nonionic detergent Triton $\mathrm{X}$ is sufficient for saturation of photosynthesis in terrestrial higher plants [27]. Even a short exposure to detergent effects causes extensive changes in photosynthesis. For example exposing for $10 \mathrm{~min}$ in water containing a few drops of liquid detergent induce the increase of photosyntesis [28]. It was concluded that detergent (Triton X-100) causes damage of the donor part of photosystem 2 in 
isolated chloroplasts [29]. Detergent treatment of the membranes resulted in loss of PS I activities [30]. Non-ionic detergent $n$-dodecyl- $\alpha$, D-maltoside cause disintegration of the potosystem II (PS II) into separated PS II in stacked and unstacked thylakoid membranes from spinach [31]. The addition of the detergent Triton $\mathrm{X}-100$ to the 'chromatophore' facilitated the photooxidative destruction of the antenna BChl [32]. In addition to inhibition of activities PHII detergent can cause morphological changes of these centres. Detergent treatment of stacked thylakoid or BBY membranes usually gives to PS II-LHC II varying size [31].

\section{CONCLUSIONS}

Detergents in the water for watering plants have adverse effect. In the bean plants which were watered with detergent water, significant changes were observed. Chlorophyll concentration dropped by $12 \%$. The activity of photosynthesis apparatus in leaves decreased by around $45 \%$.

\section{ACKNOWLEDGEMENTS}

This work was supported by Grants No. 141007 of MNRS. Authors want to thank Mr. P. Hiddinga on kindness in supporting equipments.

\section{REFERENCES}

[1] Imandel, K., Razeghi, N. and Samar, P. (1978) Tehran ground water pollution by detergent. Water, Air, \& Soil Pollution, 9, 119-122.

[2] Korshenko, A. and GasimGul, A. (2005) Pollution of the Caspian Sea. Handbook of Environmental Chemistry, Springer-Verlag Berlin Heidelberg, 5, Part P, 109-142.

[3] Adekola, B.N. and Eletta, O.A.A. (2007) A study of heavy metal pollution of Asa River, Ilorin. Nigeria; trace metal monitoring and geochemistry. Environmental Monitoring and Assessment, 12, 157-163.

[4] Zhuravel, V.E., Bezverbnaya, I.P. and Buzoleva, S.L. (2004) Microbian indication of pollution of the coastal zone of the sea of Okhotsk and Avacha Bay. Russian Journal of Marine Biology, 30(2), 121-126.

[5] Burdon, F., Bouchaud, J.P., Tannoudji, A. and Levy, C.C. (2002) Statistics \& Laser Cooling (Paperback), Cambridge University Press, UK.

[6] Lichthenthaler, K.H. and Buschmann, C. (1987) Chlorophyll Fluorescence Spectra of Green Bean Leaves. Journal of Plant Physiology, 129(1-2), 137-147.

[7] Lichtenthaler, K.H. and Riderle, U. (1988) The role of the chlorophyll fluorescence in the detection of stress conditions in plants. CRC Critical Reviews in Analytical Chemistry, 19, S29-S85.

[8] Jovanić, R.B. and Dramićanin, D.M. (2003) In vivo monitoring of chlorophyll fluorescence response to low-dose $\gamma$-irradiation in Pumpkin (Cucurbita pepo). $\mathrm{Lu}$ minescence, 18, 274-277.

[9] Aizdaicher, N.A. and Reunova, Yu. A. (2002) Effects of detergents on in vitro growth of diatom alga thalassiosira pseudonana. Russian Journal of Marine Biology, 28(5), 324-328.

[10] Vasconcelos, A., Silva, C.J.S.M., Schroeder, M., Guebitz, G.M. and Cavaco-Paulo, A. (2006) Detergent formulations for wool domestic washings containing immobilized enzymes. Biotechnology Letters, 28(10), 725-731.

[11] Ca'rdenas, L., Vidali, L., Domi'nguez, J., Pe'rez, H., Sa'nchez, F., Hepler, K.P. and Carmen Quinto, C. (1998) Rearrangement of actin microfilaments in plant root hairs responding to rhizobium etli nodulation signals. Plant Physiology, 116(3), 871-877.

[12] Nand, L. and Richa, M. (2003) Synthetic detergent induced changes in the seed inhibition pattern and dehydrogenese activity in mungbean (Vigna radiata). EcoEnvConserv, 9(3), 379-383.

[13] Park, J., Gu, Y., Lee, Y., Yang, Z. and Lee, Y. (2004) Phosphatidic acid induces leaf cell death in arabidopsis by activating the rho-related small $G$ protein GTPasemediated pathway of reactive oxygen species generation. Plant Physiology, 134(1), 129-136.

[14] Behzadipou, M., Kluge, M. and Liithjea, S. (2001) Changes in plasma membrane fluidity of corn (Zea mays L.) roots after Brij 58 treatment. Protoplasma, 217, 6569.

[15] Brandt, K.K., Hesseloy, M.E., Rosloev, E.P., Enriksen, K. and Oyrensen, J.S. (2001) Toxic effects of linear alkylbenzene sulfonate on metabolic activity, growth rate, and microcolony formation of nitrosomonas and nitrosospira strains. Applied and Environmental Microbiology, 67(6), 2489-2498.

[16] Nanba, O. and Satoh, K. (1987), Proceedings of the National Academy of Sciences, USA. 84, 109-112.

[17] Reunova, Y.A. and Ayzdaycher, N.A. (2003) Effects of detergent on chlorophyll a content and quantity dynamics of microalga Chroomonas salina (Wils.) Butch. (Cryptophyta). International Journal on Algae, 5, 106-110.

[18] Mimuro, M. and Katoh, T. (1991) Carotenoids in photosynthesis: Absorption, transfer and dissipation of light energy. Pure and Applied Chemistry, 63(1), 123-130.

[19] Green, B.R. (1988) The chlorophyll-protein complexes of higher plant photosynthetic membranes or Just what green band is that? Photosynthesis Research, 15(1), 3032 .

[20] Gadallah, M.A.A. (2004) Phytotoxic effects of industrial and sewage waste waters on growth, chlorophyll content, transpiration rate and relative water content of potted sunflower plants. Water, Air, \& Soil Pollution, 89(1-2), 33-47.

[21] Szabad, J., Lehoczki, E., Szalay, L. and Csatorday, K. (1984) Lutein-chlorophyll-a energy transfer in detergent micelles, Biophysics of Structure \& Mechanism, 1(1), 6574.

[22] Eggink, L.L., Park, H. and Hoober, J.K. (2001) The role of chlorophyll $\mathrm{b}$ in photosynthesis: Hypothesis, BioMed Central.

[23] Murphy, D.J. and Woodrow, I.E. (1984) The effects of Triton X-100 and n-octyl f-D-glucopyranoside on energy transfer in photosynthetic membranes. Biochemical Journal, 224(3), 989-993.

[24] Liu, S., Dong, F.Q., Tang, C.Q., Kuang, T.Y., Li, L.B. and Liu, Y. (2006) Photodamage to pigment in the pho- 
tosystem reaction center D1/D2/Cytochrome b559 complex. Journal of Integrated Plant Biology, 48(7), 800806.

[25] Moya, I., Silvestri, M., Vallon, O., Cinque, G. and Bassi, R. (2001) Time-resolved fluorescence analysis of the photosystem II antenna proteins in detergent micelles and liposomes. American Chemical Society.

[26] Tang, D., Jankowiak, R., Seibert, M. and Small, G.J. (1991) Effects of detergent on the excited state structure and relaxation dynamics of the photosystem II reaction center: A high resolution hole burning study. Journal of Photosynthesis Research, 27(1), 19-29.

[27] Ivanov, B.N., Ignatova, L.K. and Romanova, A.K. (2007) Diversity in forms and functions of carbonic anhydrase in terrestrial higher plants. Russian Journal of Plant Physiology, 54(2), 143-162.

[28] Santacruz-Ruvalcaba, F., Gutiérrez-Pulido, H. and Rodríguez-Garay, B. (1999) Efficient in vitro propaga- tion of agave parrasana berger. Plant Cell, Tissue and Organ Culture, 56(3), 163-167.

[29] Klimov, V.V., Karapetian, N.V. and Krasnovskiı̌, A.A. (1975) The effect of detergent Triton $X=100$ on the light induced changes in the fluorescence yield of chloroplasts. Journal of Molecular Biology (Mosk), 9, 219-226.

[30] Katoh, S. (2003) Early research on the role of plastocyanin in photosynthesis. Photosynthesis Research, 76(1-3), 255-261.

[31] Dekker, J.P., Germano, M., Roon, H. and Boekema, E,J. (2002) Photosystem II solubilizes as a monomer by mild detergent treatment of unstacked thylakoid membranes. Photosynthesis Research, 72(2), 203-210.

[32] Vernon, L.P. (2003) Photosynthesis and the Charles F. Kettering Research Laboratory. Photosynthesis Research, 76(1-3), 379-388. 